\title{
Emerging Adulthood, a Pre-adult Life-History Stage
}

\author{
$Z^{\prime}$ ev Hochberg ${ }^{1 *}$ and Melvin Konner ${ }^{2}$ \\ ${ }^{1}$ Faculty of Medicine, Technion Israel Institute of Technology, Haifa, Israel, ${ }^{2}$ Program in Neuroscience and Behavioral Biology, \\ Emory University, Atlanta, GA, United States
}

The duration of human maturation has been underestimated; an additional 4-6-year pre-adult period of "emerging adulthood," should be included in models of human maturation. It is a period of brain maturation, learning about intimacy and mutual support, intensification of pre-existing friendships, family-oriented socialization, and the attainment of those social skills that are needed for mating and reproduction. We propose that emerging adulthood is a life-history stage that is a foundation of the high reproductive success of human beings. The period of emerging adulthood has an evolutionary context and developmental markers, and we present evidence that supports the idea that emerging adults require protection because they are still learning and maturing.

OPEN ACCESS

Edited by:

Margaret Cristina Da Silva

Boguszewski,

Federal University of Paraná, Brazil

Reviewed by:

Giorgio Radetti,

Ospedale di Bolzano, Italy Jean-Pierre Chanoine,

University of British

Columbia, Canada

*Correspondence:

Ze'ev Hochberg

rprzeev@technion.ac.il

Specialty section:

This article was submitted to

Pediatric Endocrinology,

a section of the journal

Frontiers in Endocrinology

Received: 22 July 2019 Accepted: 17 December 2019

Published: 14 January 2020

Citation:

Hochberg Z and Konner M (2020) Emerging Adulthood, a Pre-adult Life-History Stage.

Front. Endocrinol. 10:918 doi: 10.3389/fendo.2019.00918
Keywords: life history, adolescence, human evolution, hominin, comparative development, brain development

\section{INTRODUCTION}

Growing evidence suggests that an individual at the end of adolescence cannot be considered to be an adult when using physical, physiological, intellectual, social, emotional, and behavioral measures. When adolescents in developed societies mature and achieve adult body size, their behavior often remains immature. Specialists in adolescent medicine have recognized this incongruity, and have redefined adolescence to include young adults up to age 24 years, of whom many have not yet assumed adult roles $(1,2)$. Reproduction in contemporary forager societies also begins several years after adolescence and post-adolescent individuals are often limited in their gathering and/or hunting skills (3-5). Compared to other mammals, primates produce few offspring. Humans have an even slower growth rate than that of non-human primates of comparable size, but human growth may be even more prolonged than is generally realized.

Arnett proposed emerging adulthood as a phase of life between adolescence and full-fledged adulthood, with distinctive demographic, social, and subjective psychological features $(6,7)$. This life- history stage applies to individuals aged between 18 and 25 years, the period during which they become more economically independent by training and/or education. Previously, the psychodynamic theorist Erik Erikson identified a stage that he called a prolonged adolescence or psychosocial moratorium in young people in developed societies $(8,9)$. Much more recently, Hopwood and colleagues explored genetic and environmental influences on personality development during the transition to adulthood in same-sex male and female monozygotic and dizygotic twins assessed in late adolescence (approximately age 17 years), emerging adulthood ( $\sim 24$ years), and young adulthood ( $\sim 29$ years) (10). Their genetically-informed results support a life-course perspective on personality development during the transition to adulthood. In addition, the United Nations has identified youth, defined as the period from 15 to 24 years of age, as a period of vulnerability worldwide and has made it a priority for multiple interventions (11). 
Here, we use an evolutionary approach in order to understand emerging adulthood, arguing that it is not just a sociological transition period but a biological life-history phase. Trait variability, whether it is molecular, cellular, physiological, morphological, or behavioral, is the leading edge of evolution. Together with genetic evolution, plasticity in developmental programming has evolved to provide the organism with traits that can secure its survival and reproductive success (12). Lifehistory theory is a powerful tool for understanding child growth and development from an evolutionary perspective $(2,13,14)$. We provide evidence that emerging adulthood exists in some other mammals, which implies genetic evolution, and we discuss emerging adulthood in foraging as well as developed societies, which implies the occurrence of adaptive plasticity and cultural influences. We propose that genetic and cultural evolution have interacted to produce the emerging adulthood stage in human life history.

\section{DEFINING THE TRANSITION FROM ADOLESCENCE TO EMERGING ADULTHOOD}

Determining the exact time of transitions between life-history stages is challenging (13). Saltations (growth spurts) and transitions occur during human growth $(15,16)$, and stages have a central place in evolutionary life-history theory, but the turning points are theoretical constructions in which some aspects of a transition are highlighted.

Puberty produces an endocrine transformation with striking somatic and behavioral changes, especially in body image, sex identity, aggression, and impulsivity. To define a maturational stage between adolescence and adulthood, we need first to define the end of adolescence. During this transition, growth velocity decelerates, blood and tissue hormone levels increase, aggression becomes less overt, and learning and maturation mitigate hormonal impact.

Using maturational measures avoids the pitfalls of defining emerging adulthood according to chronological age. For example, the Tanner scale of adolescent development is based on external primary and secondary sex characteristics. Tanner stage $\mathrm{V}$ recognizes the conclusion of puberty in boys when the testicular volume is $>20 \mathrm{ml}$ and the length of the penis is $>14 \mathrm{~cm}$ (17) and in girls when the breast reaches final adult size and the areola returns to the contour of the surrounding breast with a projecting central papilla (18).

Here, we define the transition between adolescence and emerging adulthood as occurring when growth returns to its prepubertal trajectory and the boy or girl is at Tanner stage IV (19). Boys at this stage have a testicular volume between 12 and $20 \mathrm{ml}$, their scrotal skin darkens, and the length of their penis is $\sim 10 \mathrm{~cm}$. Girls at this stage have experienced menarche, their breasts are of adult size and elevated, and the areola and papilla form a secondary mound which projects from the contour of the surrounding breast. Body composition continues to change during emerging adulthood, in terms of relative fat mass, lean body mass, and total body bone mineral content and bone mineral density increase (20), but the most important maturational changes after adolescence, even if defined as the end of Tanner Stage 4, are in the brain.

Brain size may be a pacemaker in mammalian life history (21), and it underlies the remarkable human capacity for learning and communication, but the length of the brain's developmental trajectory was until recently underestimated. It is now clear that brain development does not stop with the completion of puberty when adult brain size is attained. Brain maturation continues beyond adolescence, extending until around age 25 years, and this recently discovered prolongation provides critical support for emerging adulthood as a post-adolescent maturational stage (22). Compared to other primates, human newborns are neurologically and behaviorally altricial because many aspects of brain development are protracted, including that of the prefrontal cortex (23). The cortical architectural units or minicolumns in the prefrontal cortex of humans are wider than those of the great apes, an increase that occurs after puberty in humans, but not in chimpanzees (24). In chimpanzees, but not in humans, myelination becomes complete at about the time of sexual maturity (25). Interestingly, human brain regions with protracted development are the same that have undergone the greatest degree of volumetric enlargement in primate evolution (26).

In a large-scale longitudinal pediatric neuroimaging study, brain maturation was found to continue after adolescence: postadolescent increases in white matter are linear while the changes in the cortical gray matter are non-linear. Cortical white matter in particular continues to increase into the mid-twenties, which is likely related to the efficiency and speed of cortical connectivity $(27,28)$. In another study, Sowell and her colleagues spatially and temporally mapped brain maturation in North American adolescents (age 12-16 years) and young adults (age 23-30 years) using a whole-brain, voxel-by-voxel statistical analysis of high-resolution structural magnetic resonance images (29). They found that the pattern of brain maturation during these years was distinct from earlier development and was localized to large regions of the dorsal, medial, and orbital frontal cortex and lenticular nuclei. They also reported relatively little change at other brain locations. They concluded that cognitive function improves throughout adolescence, and this improvement is associated with parallel post-adolescent reductions in gray matter density (as white matter increases) in frontal and striatal regions. It has been argued that such brain changes should mitigate the guilt of adolescent delinquents who have not yet gone through them (30-32).

Asato and colleagues also investigated white matter maturation during adolescence using diffusion tensor imaging and reported that (a) pubertal hormones influence white matter development and maturation and (b) white matter connectivity and the executive control of behavior is still immature in adolescence (33). Jolles and colleagues investigated the association between whole-brain functional connectivity and cognitive and emotional functions in children (11-13 years) and young adults (19-25 years) (34). Although they found similar patterns of functional connectivity in children and young adults, there were differences in the size of the functionally connected 
regions and the strength of functional connectivity. Thus, functional connectivity continues to change during and after adolescence, and these developmental differences in functional connectivity patterns were associated with higher cognitive or emotional functions and basic visual and sensorimotor functions.

In another study comparing social and emotional functioning of children, adolescents, and young adults, by analyzing the age-dependent development of five functionally distinct cingulate-based intrinsic connectivity networks (ICNs), Kelly and colleagues provide additional evidence that brain maturation extends beyond adolescence into young adulthood (35). They found that the pattern of correlation with voxels proximal to the seed region of interest was age-dependent: the pattern was diffuse in children (mean age 10.6 years), was less diffuse in adolescents (mean age 15.4 years), and showed signs of becoming focal in young adults (mean age 22.4 years). Also, the greatest development occurred in those ICNs associated with social and emotional functions. Finally, in their study of the brains of 103 healthy subjects aged 5-32 years using diffusion tensor tractography, Lebel and Beaulieu provide further evidence that brain maturation continues from childhood into adulthood (36). Association tracts show within-subject maturation of measures indicative of myelination and axon density.

Collectively, these studies provide strong evidence that brain development and maturation continue in young adulthood; the idea that brain maturation is finalized during adolescence is no longer tenable. Psychologically, emerging adulthood is a stage when an individual's cognitive abilities increase to reach their peak in their fourth decade and possibly beyond (37). Schaie and colleagues included 13 measures of crystallized abilities influenced by schooling and experience. The critical abilities from this perspective are those that enable the learning of new things, that is, working memory and fluid intelligence; these, as well as processing speed (38), peak in the mid 20s.

Emerging adulthood is also a social stage: it is a period of learning about intimacy and mutual support, intensification of pre-existing friendships, family-oriented socialization, political awareness, developing new relationships, and the attainment of biosocial skills that are needed for successful mating and reproduction. Finally, it is also a stage of understanding self-concepts and ideal concepts, emphasized interpersonal reactivity and obligation, self-expressiveness, and contempt toward particular ideologies (39). The attainment of these cognitive, emotional, and social abilities is the result of a complex interplay of maturation and interaction with the environment, but it is now possible to say that at least in the earlier years of emerging adulthood, they are correlated with and possibly caused by brain maturation. There is also evidence that brain size growth continues into the third decade in some individuals. In these individuals, hypothalamic maturation, puberty, and the resultant hormonal surges are dissociated from and even precede development and maturity of frontal cortex $(40,41)$.

Emerging adulthood is associated with other physiological changes, such as bone mineral accretion, the completion of growth, and [frequently] first reproduction. Hence, emerging adulthood begins as a physiological, but most importantly a neural transformation in which behavioral and social functions interact, with consequences for impulse control in domains that have put the individual at risk during puberty. We will argue that this life-history phase has unfolded throughout hominin evolution. In Figure 1 we show the timeline of maturation of the main physical, behavioral and social traits.

\section{GROWTH-RELATED DEFINITION OF THE TRANSITION TO EMERGING ADULTHOOD}

To define the transition from adolescence to emerging adulthood, we use the age at which growth velocity returns to prepubertal levels (Figure 2A). The adolescent growth spurt can be identified from the growth velocity curve, and its takeoff is signaled when the rate of growth changes from deceleration to acceleration at the end of the juvenile stage (13). This inflection point marks the beginning of the adolescent growth spurt. The point at which the curvilinear growth velocity spurt returns to the pretakeoff velocity defines for us the end of adolescence and the beginning of emerging adulthood. This refinement of the "return to [pre-]takeoff velocity," which was previously proposed by Leigh and Park (42), is essential for understanding the human pubertal growth spurt (43). This model, displayed in Figure 2A, explains the apparently diminished peak height velocity in delayed puberty and is the basis of adult height predictions for prepubertal children.

In an allometric analysis of 21 species of anthropoid primates, the age at return to pre-takeoff velocity and the adult body mass are positively correlated in both females and males (Figure 2B). The age at return to pre-takeoff velocity occurs later in human beings than other primates because of the lateness of our growth spurt when body mass is considered (42). Overall, the growth spurt in most primates is quite minimal, and little is known about the relationship between the age at return to prepubertal growth velocity and the appearance of secondary sexual characteristics at puberty. Takeoff velocity occurs early in gorillas, and despite their greater body mass, female gorillas become sexually mature at a younger age than female chimpanzees (44). Similar to humans, vervet (Cercopithecus aethiops) and rhesus monkeys (Macaca mulatta) show a relatively late return to prepubertal growth velocity. Interestingly, this positive correlation between the age at return to prepubertal growth velocity curve and body mass also exists in six small-scale societies described in Walker's Database for Indigenous Cultural Evolution (http://dice. missouri.edu/) (Figures 2C,D).

\section{THE EVOLUTIONARY CONTEXT OF EMERGING ADULTHOOD}

\section{Evolutionary Life-History Theory}

Life history is defined as the allocation of an organism's energy toward growth, maintenance, reproduction, raising offspring to independence, and avoiding death (45), and adaptation to environmental changes requires the selection of certain lifecycle traits $(46,47)$ (Figure 3). Evolutionary life-history theory attempts to explain and predict tradeoffs that optimize energy expenditure, reproductive advantage, and risk (2, 14, 48, 49). 


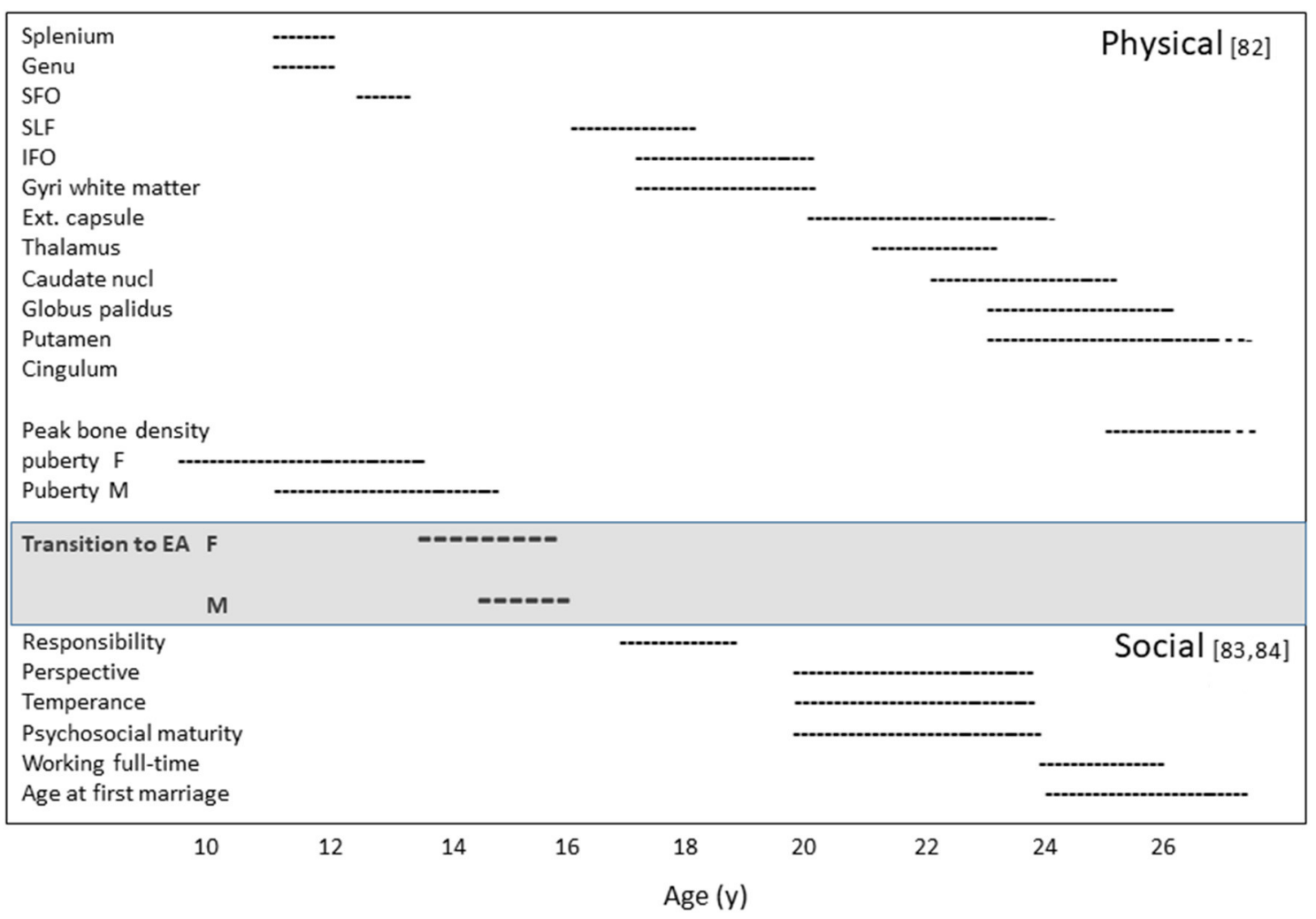

FIGURE 1 | Maturation timeline: (Upper) the age range to complete physical maturation (82). (Lower) the age range to complete social maturation (83) and US Bureau of Labor Statistics, 2014. SFO, The subfornical organ; SLF, The superior longitudinal fasciculus; IFO, anterior insula/frontal operculum complex; EA, emerging adulthood; F, female; M, male (82-84).

Central to the concept of sexual selection is the attainment and optimization of reproductive competence, and the key traits for selection are growth, maturation, and the age at transition to adulthood and sexual reproduction (12).

Human beings and the great apes share similar traits including, to some extent, emerging adulthood. We know relatively little about neurological maturation in non-human primates, but we do know that non-human great apes have a 2 -year period of post-menarcheal infertility (50), extended in human foragers to 3 years (51). Low reproductive success among young females is a general primate phenomenon (52). Male preference for fully developed adult females has been described in 15 primate species (52). Goodall reported that after menarche, which usually occurs at age 10 years, female chimpanzees average 19 full-size cycles before becoming pregnant for the first time at age 12 years (53). Moreover, they will have about 60\% of their lifetime sexual encounters during this post-menarcheal period. Unlike gorillas, chimpanzees (Pan troglodytes), and bonobos (Pan paniscus) live in multi-male and multi-female groups and mate more often than needed to conceive. Accordingly, primatologists have suggested that adolescent sterility is a period in which sexual and social skills are practiced without responsibility for the care of a newborn (53). In their emerging adulthood, female vervet monkeys (Cercopithecus aethiops) display a high degree of interest in young infants and will touch, cuddle, carry, and groom infants whenever they can. Lancaster interpreted this play-mothering by young females as an opportunity to practice maternal behavior and ease into their expected maternal role in society (54). Fecundity in males depends on age, size, and experience. Similar to humans, where reproductive success is in-line with hunting ability (55) reproductive success among the Barbary macaques (Macaca sylvanus) is much lower in young than adult males (56). In male chimpanzees, pre-fertility copulation is very common (53).

While it seems impossible to ascertain the life-history stages of early hominids, the timing of their dental maturation from the fossil record has shed some light on their stages (see below). Australopithecines are anatomical intermediates between apes and human beings and chimpanzees and bonobos are often regarded as living species that can to some extent represent the australopithecines. Based on fossil dental specimens, australopithecined resembled wild chimpanzees, not modern humans, in life-history stages (57). Fossil Homo species matured more slowly and the attainment of certain developmental milestones, such as the onset of puberty, adolescence, and first reproduction, probably occurred later, in parallel with their increasing longevity, body mass, and height (Figure 3). 


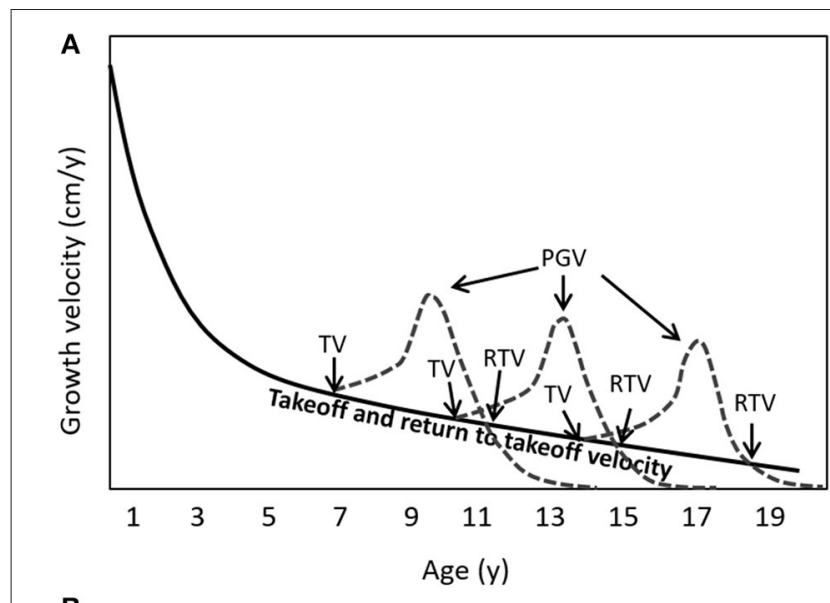

B

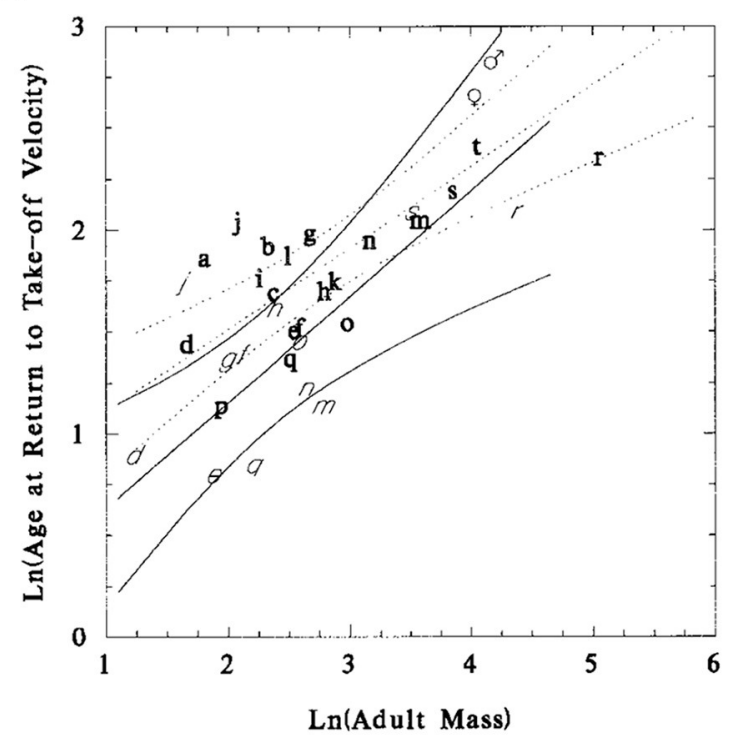

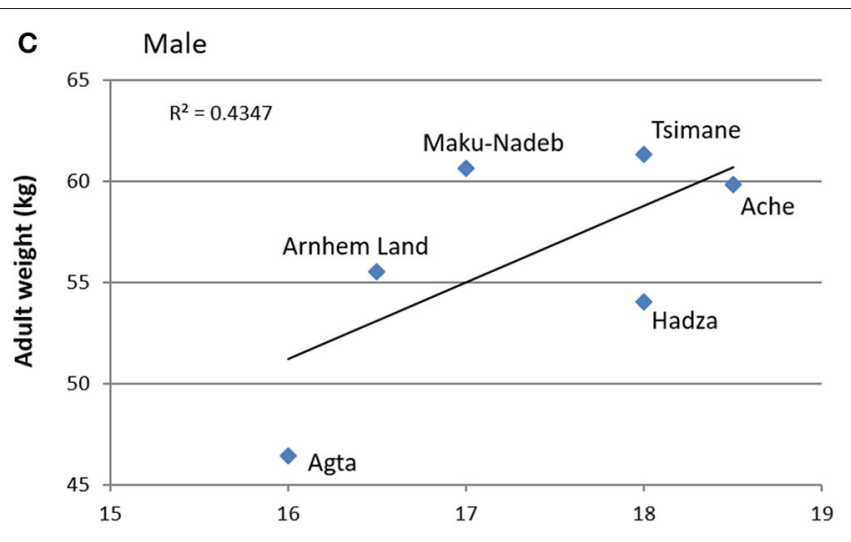

D

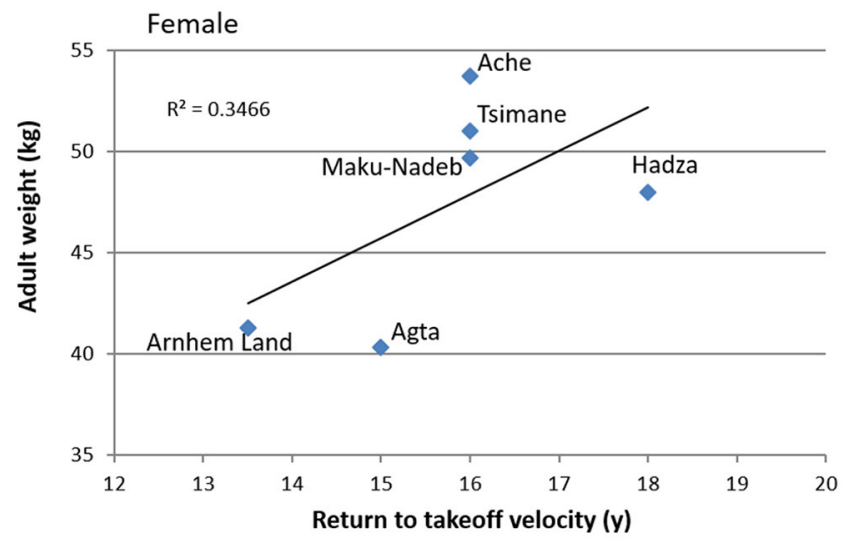

FIGURE 2 | The concept of the return to prepubertal growth velocity curve as a life history mile stone. Here, we define the return to take-off velocity as the transition from adolescence to emerging adulthood. (A) Schematic representation of the age-dependent pubertal take-off velocity and the return to prepubertal growth velocity curve; in girls the return to takeoff velocity coincides with menarcheal age in the early, average, and late maturers. The age-dependent decline in peak height velocity is a function of the decelerating takeoff velocity and returns to the prepubertal growth velocity curve. PGV, peak growth velocity; TV, takeoff velocity; RTV, return to prepubertal growth velocity curve. (B) The age of return to prepubertal growth velocity curve as a function of adult body mass in 21 primate species. Observations are derived from captive primates held at zoological parks and primate centers. With permission from Leigh and Park (42). a-Cebus apella, b-Cercopithecus aethiops, c-Cercopithecus mitis, d-Cercopithecus neglectus, e-Erythrocebus patas, $\mathrm{f}$-Cercocebus atys, $\mathrm{g}$-Macaca arctoides, $\mathrm{h}-$ Macaca fascicularis, $\mathrm{i}-$ Macaca fuscata, j-Macaca mulatta, k-Macaca nemestrina, I-Macaca silenus, m-Papio hamadryas, n-Mandrillus sphinx, o-Colobus guereza, $\mathrm{p}-$ Presbytis entellus, $\mathrm{q}$-Presbytis obscura, $\mathrm{r}$-Gorilla gorilla, $\mathrm{s}-$ Pan paniscus, $\mathrm{t}-$ Pan troglodytes. (C,D) - average adult body weight as a function of the age at return to prepubertal takeoff growth velocity of males (C) and females (D) in six predeveloped societies. Data from http://dice.missouri.edu.

A life-history tradeoff is a fitness cost that occurs when a beneficial change in one trait is linked to a detrimental change in another trait (58). According to Charnov, a life-history tradeoff also entails an invariant in an underlying parameter that the life cycle stabilizes or is constrained by (59). The Charnov model of mammalian life-history evolution (59) derives the flow of life-history consequences from the adult mortality rate:

Adult mortality $\square$ Age at maturity $\square$ Adult weight $\square$ Fecundity $\square$ Juvenile mortality.

In this model, any factor that decreases adult mortality, such as large adult body mass, sociality, or a low-predation environment, favors delayed maturation. Reproductive value
(RV) increases with body mass while growth rates decline. The optimal age to stop investing in growth is when the expected $\mathrm{RV}$ starts to decline. Body mass increases during growth, which stops when body mass is optimal, so juvenile survival becomes important when maturation is delayed. Increasing juvenile survival and extending the adolescent life-history stage increases that individual's RV. Hence, emerging adulthood is highly favored.

The offspring number of most species with a large body size is small. Additionally, juvenile mortality decreases when reproduction is late, and late reproduction is associated with high fertility. Late reproduction should decrease fitness 


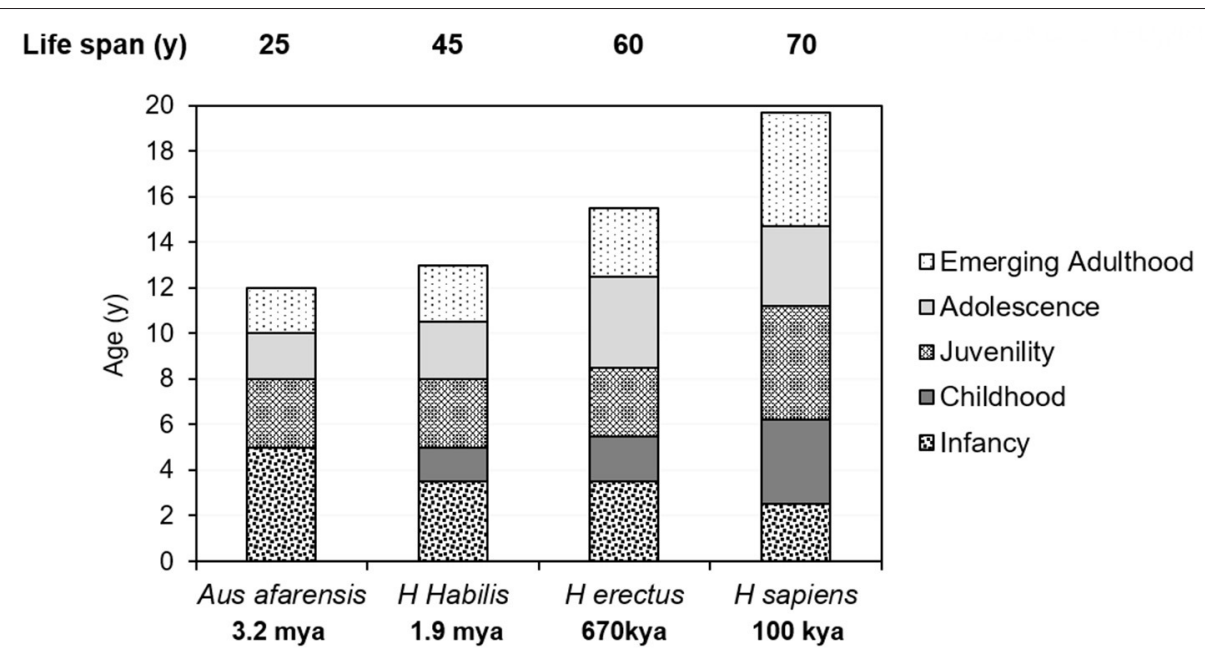

FIGURE 3 | Comparison of the life-history stages and the newly defined emerging adulthood of Australopithecus afarensis, Homo habilis, $H$. erectus, and $H$. sapiens.

(60), but several tradeoffs could influence the prolonged period of emerging adulthood in human life-history strategies: reproducing at an earlier or later age; reproducing at a young age or continuing to grow and develop; and being an adult parent with a large parental investment in each offspring of a small family or a young parent with a small parental investment in each offspring of a large family. The Charnov model predicts that a long life span will be associated with slow development, iteroparity (repeated reproduction), a single offspring, and long parental care (59). It was recently suggested that slow rates of growth, reproduction, and aging among primates reflect their low total energy expenditure (61). Emerging adulthood in modern societies is part of the historical lengthening of both ends of the pre-reproductive life span of human females (early puberty and late reproduction) in response to improved nutrition and decreased infection $(62,63)$. Microevolutionary tradeoffs that might underlie an extended emerging adulthood stage of life history include the allocation of energy to growth or reproduction, and the energy investment in courtship or parenting. Indeed, performing the sexual act in some species requires good cognitive ability and specific sexual behaviors (64). During human evolution, the acquisition of certain abilities resulted in the lengthening of maturation and development.

Brain size in mammals is correlated with longitudinal growth, and both have increased during human evolution (65). Brain size and cultural complexity have concomitantly increased over the last 2 million years with two possible periods of accelerated increase. The first occurred during the early evolution of the genus Homo, the second during the rise of Homo sapiens.

Using Charnov's model, we also suggest that emerging adulthood is a life-history stage that is a foundation of the high productivity of human beings: the metabolic potential of human beings exceeds the metabolic requirements of survival and this excess is first used to support growth and brain maturation before being allocated to reproduction. Another critical adaptation in hominin evolution was the ability to improve the food supply by establishing a rich and stable food base through the control of fire (Homo erectus), cooking (early Homo sapiens or earlier) $(66,67)$, and exploiting coastal food resources (shellfish) (68).

Despite the fact that the human juvenile (including emerging adulthood) and adult periods are longer than that of the chimpanzee and that human infants are larger than chimpanzee infants at birth, hunter-gatherer women characteristically have higher fertility than chimpanzee females (69). In anthropoid primates (monkeys, apes, and humans), non-maternal care predicts earlier weaning, shorter birth spacing, and higher reproductive success (70). Parental provisioning of the weaned offspring, an aspect of cooperative breeding (71), is crucial (72, 73). Here, we argue that anatomically modern human parents care for their offspring throughout their offspring's adolescence and emerging adulthood, and this extended period of care is longer than that of other primates.

The unique evolutionary path to the genus Homo was shaped by an increasing reliance on calorie-dense, large-package, skillintensive food resources, "which, in turn, operated to produce the extreme intelligence, long developmental period, threegenerational system of resource flows, and exceptionally long adult life characteristic of our species" (74). Kaplan and Robson emphasized the role of human males in provisioning meat to their family and tribal members (74). They also highlighted the contributions of grandmothers and other family and band members to provisioning and childcare, enhancing survival and success in emerging adulthood.

Although, the average menarcheal ages of the gorilla, the bonobo, and the chimpanzee are 7-8, 9, and 11 years, respectively, their ages at first birth are 10-12, 13-15, and 14-15 years (75). Despite their rapid development compared with humans, the great apes have a distinct period of postmenarcheal. In parallel with other great apes, the menarcheal age of human forager populations ranges from 13 to 19 years, and their first birth occurs about 4 years later when they are between 17 and 23 years of age $(62,76)$ (Figure 4). In contrast 


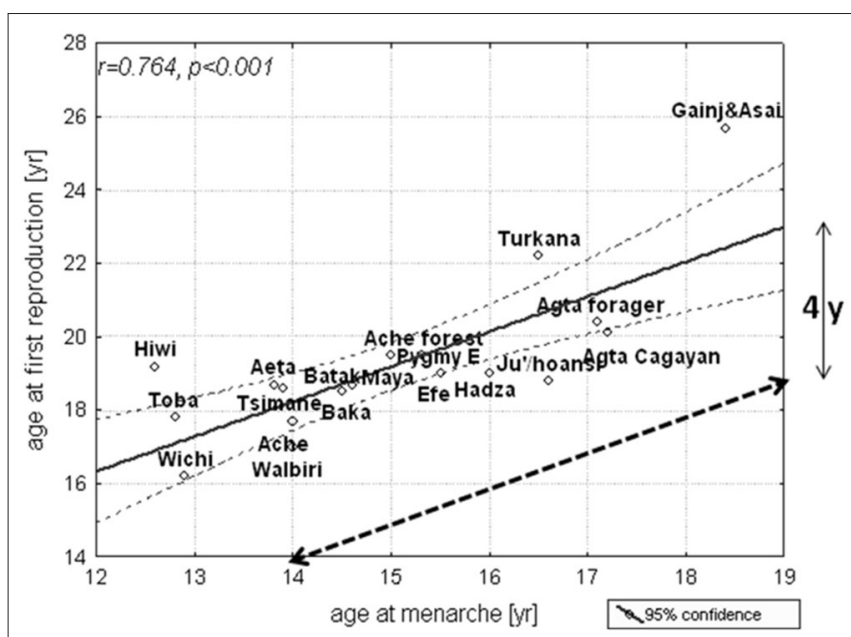

FIGURE 4 | Age at menarche and first birth among some natural fertility societies; mean and 95\% confidence limits. The dashed line is the age at menarche when plotted against the age at first reproduction [reproduced with permission from Hochberg et al. (76)].

to great apes, primiparous women of human forager populations are provisioned by mature adults, such as grandmothers, who are usually post-reproductive $(77,78)$; their husbands, who are typically several years older and have often passed through the emerging adulthood stage of their life history before marriage; and other adults $(3,79-81)$.

Despite similarities among primates, the prolongation of dependency during emerging adulthood (Figure 3 ) is unique to human life history, and is part of the evolutionary success of Homo sapiens. In the light of the knowledge we have gained from other primates, we need to improve our existing definitions of the beginning and end of emerging adulthood in primates in terms of physical traits.

\section{Development of the Human Reproductive Strategy}

Across forager societies, there is a consistent 3-4-year period between menarche and the birth of the first child (Figure 4) and adult reproductive behaviors are learned during this period of emerging adulthood. The evolution of human development culminated in environment-dependent and late reproductive maturation. According to life-history theory $(59,85)$, a reduction in juvenile and adult mortality (86) postponed reproduction and necessitated substantial parental investment in each offspring.

Sexual behavior develops according to a species-specific, genetically controlled, maturational plan in which the age at first reproduction occurs within a specific age range (87). Darwinian theory yields testable predictions about mating strategies and behaviors, which include jealousy, fidelity, pursuit, diffidence, the number of new sexual partners per year (partner frequency), and gender roles and behaviors customarily displayed in emerging adulthood (88). These predictions also apply to adult patterns of intra- and intersexual aggression $(89,90)$. Here, we offer an evolutionary model for this transformative life-history stage, emerging adulthood.
Despite cross-cultural variations in the age of initiation of sexual activity and the age at marriage, the period of emerging adulthood in all cultures involves readiness for mating. Strong emotions often accompany early sexual activity. During adolescence, the frequency of depressive episodes is temporarily increased in boys and especially in girls (91-93).

Sex hormones intensify adolescent behavioral and psychological changes (94-96), but in emerging adulthood and into adulthood, average rates of depression, anxiety, and risk-taking decline. Interestingly, serum testosterone levels continue to rise after puberty and peak in the third decade in male humans (97). However, this age-dependent increase in serum testosterone levels does not occur in chimpanzees: serum testosterone levels are higher in adolescent chimpanzees (age $7-10$ years) than in adults (age $>11$ years) (98). Male and female sex drive may be intensified and/or enabled by the activational effects of the sex steroids, as part of a switching mechanism that re-allocates resources from growth to reproductive activity during emerging adulthood (99). If the same genes allocate the energy that is required for growth and reproduction, these genes could exhibit antagonistic pleiotropy and mediate the tradeoff between growth and reproduction (100). The "fight or flight" response to perceived threat influences life-history tradeoffs during development $(101,102)$. As part of their readiness for mating, the bullying behavior of adolescent males diminishes at the time of transition to emerging adulthood $(103,104)$. This could be due to adolescents learning subtler ways of competing, they still vie for dominance and resource control. This may help explain why the mean age difference between men and women at the time of their first marriage in 191 national populations and traditional societies is 3.5 years (105).

\section{Adolescence and Emerging Adulthood Among the !Kung and Other Foragers}

Contemporary forager societies are to some extent modern representatives of pre-agricultural forager societies. The !Kung were until recently foraging people of the Kalahari Desert, whose demography and life history have been extensively studied (81, 106). Their average age of menarche is 16.6 years (range 16-18 years), and about $50 \%$ were married before menarche to men averaging 10 years older. Their age at first childbirth was 19 years (range 17-22 years) (106). This 3-year period of between the age of menarche and the age at first birth is probably due to subfertile ovarian cycling. Although their husband's sexual advances were supposed to be delayed until menarche, women reported that this period was often stressful (107). This 3-year period is important for a newly married !Kung woman for at least two reasons. First, she gradually learns to adopt adult roles and acquire adult sexuality without having to deal with the consequences of pregnancy and feeding a family. Second, she usually lives near her mother, even after the first birth, because she is dependent on her mother, father, and extended family before moving to her husband's village-camp after a second child $(81,107)$. Although !Kung women become socially responsible mothers with two or more children by their mid-20s, they are typically still being provisioned by their families (81). Psychosocial development 
during emerging adulthood is substantially longer in boys than in girls, and the transition from adolescence to adulthood is gradual (108). !Kung boys learn hunting and other subsistence skills and are permitted to accompany adult men on hunting trips from their mid-teens. But the husband's obligation to provision his family with meat is also aided by relatives during the period of emerging adulthood.

To what extent do the !Kung resemble other hunter-gatherer societies? The acquisition of subsistence skills is a very long process among the closely related San of the Okavongo Delta, Botswana (5). Mongongo nuts are a staple food (as for the !Kung) and the ability to crack these nuts is age-specific because nut-cracking requires skill; arm strength is less important than age. Plotted against age, the ability follows an inverted Ushaped function across the lifespan, and this time-dependent function is a good example of the adaptive evolutionary value of emerging adulthood beyond adolescence. Success at nut-cracking is minimal until the late teens and then this skill improves until midlife.

The Hiwi Indians of Venezuela and the Aché Indians of Paraguay are traditional hunter-gatherer groups whose hunting and subsistence skills gradually increase throughout young adulthood (109). Although Aché girls collect insect larvae for subsistence, children of the two tribes under age 10 years do almost no foraging and especially no hunting until their teenage years. Specifically, the skill of gathering honey and palm fiber of Aché boys and Hiwi girls progressively increases to levels that are about half of their peak adult values in adolescence. The age at which the hunting skills of Hiwi and Aché men are at their best is the late 30s, and the age at which Hiwi and Aché men and women reach their peak gathering skills for honey and palm fiber occurs is even later.

Tsimane foragers of Bolivian Amazonia are also relevant to the long pre-adult life history of modern humans (4). Based on hunting returns and specific skill tests, the peak performance of hunters is only reached several years after the completion of a long childhood and adolescence; hunters must first learn to recognize the sounds, smells, tracks, and feces of critical prey species, and then learn to hunt by sightings, pursuits, and attempted kills. The hunting performance and ability of Tsimane foragers is another example of a skill whose acquisition depends more on age than strength.

Thus, the evidence from foraging societies and the conditions to which humans became adapted during our evolution show that neither reproductive behaviors (i.e., parenting and the ability to manage the relationship with a spouse) nor subsistence skills are mastered by the end of adolescence. Even in societies where children forage from an age as young as four, their efficiency as young adults remains lower than that of their mothers (110). Blurton Jones and Marlowe confirmed increases in skill and performance with age in the Hadza, hunter-gatherers of northern Tanzania. For example, the accuracy when shooting with a bow and arrow among men Hadza people increases with age and reaches its peak at age 25 years (111). From such findings, Blurton Jones and Marlowe concluded that one cannot assume that the age-dependent increase in performance and ability is entirely due to learning and/or practice; the increase may also be due to increases in an individual's size and strength (111). The importance of size and strength is confirmed by a study of spearfishing and shellfishing efficiency among the Meriam, who live on the Mer and Dauer islands in the eastern Torres Strait. For fishing and spearfishing, which are cognitively difficult, Bird and Bird found no significant amount of variability in return rates because experiential factors correlated with age. However, for shellfish collecting, which is relatively easy to learn, they found strong age-related effects on efficiency (112). From the evidence collected from various foraging societies around the globe, performance proficiency of subsistence skills of individuals increases with age and only peaks when they transit from emerging adulthood into adulthood in their twenties or later. These findings confirm that the period of emerging adulthood is marked by age-dependent maturation, ongoing brain development, strength accrual, and learning, and is a key adaptation for human survival and reproduction.

\section{SECULAR TRENDS IN ADOLESCENCE AND EMERGING ADULTHOOD}

Menarcheal age has declined in the U.S. and Europe for over a century $(113,114)$. It has declined by 4 years over the past 150 years, and the age at peak height velocity in the pubertal growth spurt has also decreased by 4 months per decade (114). An evolutionary approach to this secular trend challenges the concept that early adolescence is a disease process, and suggests that contemporary reproductive and life-history strategies are reflected in the substantial increase in the presentation of females with early-onset adolescence (115-118). Part of the misconception that early adolescence is a pathological condition is related to the assumption that the transition from adolescence to adulthood is direct. The subfertility of emerging adulthood can be explained by the period between the age at menarche, which is 12.5 years, and the modeled optimal age at first birth of 18 years (119). Indeed, puberty is followed by subfertility in adolescence and emerging adulthood (120) due to a high proportion of nonovulatory cycles (121). Currently, there is no evidence for a secular trend in the age at first consistent ovulation.

Despite liberal mores and adolescent sexual activity, early childbearing was uncommon in pre-agricultural societies. In a non-industrial traditional society, a girl who begins to menstruate at age 15 years can take her place in that society at age 19 years as a young mother after a 4-year period of emerging adulthood and be supported by the institutions of marriage and an extended family (Figure 4) (76). In developed societies, the period of emerging adulthood of a girl who begins to menstruate at 12 years is prolonged, with slow maturation of the prefrontal cortex and other brain structures and late myelination until at least age 25, producing the mismatch between early-onset of puberty and late mental maturation in contemporary developed societies (116). It is the later part of this period of mismatch that we define as emerging adulthood, a time when young adults are still immature in their judgment and incapable of performing adult tasks (82). 


\section{SUMMARY AND CONCLUSIONS}

The idea that one of the outcomes of human evolution is a very prolonged period of adolescent growth and delayed maturity is old, and is consistent with life-history theory, comparative primatology, and the hominin fossil record. We suggest in addition that emerging adulthood is a life-history stage that is part of the foundation the high productivity of human beings: our metabolic potential exceeds the metabolic requirements of survival and this excess is first used to support growth and brain maturation before being allocated to reproduction. We contend that the duration of human maturation has been underestimated, and that an additional 4-6-year pre-adult period, which (following Arnett) we call emerging adulthood, should be included in human life history. Recent imaging studies have shown that brain development continues throughout emerging adulthood; maturation of the neocortical association areas, notably the frontal lobes, extends into the mid-twenties, and is still incomplete long after the end of puberty and linear body growth. There is now abundant evidence that the frequency of behavioral disturbances of adolescence, such as unplanned sexual activity, risk-taking, impulsivity, depression, and delinquency, declines after adolescence despite persistent high levels of gonadal hormones. The most likely explanation for the transient nature of these behavioral disturbances of adolescence is continuing myelination of the frontal cortex and other brain regions that are involved in the executive control of impulses and emotions.

Adolescence is often delayed in foraging societies, resembling our human environments of evolutionary adaptedness. Since the women in these societies have late menarche and are subsequently subfertile, the age of these young women at the time of first birth is 19 years and their husbands are generally several years older. These young parents are strongly supported by older family members, who supply needed food and advice. The mastering of subsistence skills takes many years and an individual generally becomes proficient in these skills in their fourth decade.

\section{REFERENCES}

1. Sawyer SM, Afifi RA, Bearinger LH, Blakemore S-J, Dick B, Ezeh AC, et al. Adolescence: a foundation for future health. Lancet. (2012) 379:1630-40. doi: 10.1016/S0140-6736(12)60072-5

2. Hochberg, Z. (2012). Evo Devo of Child Growth: Treatize on Child Growth and Human Evolution. New York, NY: Wiley.

3. Burdge GC, Lillycrop KA, Phillips ES, Slater-Jefferies JL, Jackson AA, Hanson MA. Folic acid supplementation during the juvenile-pubertal period in rats modifies the phenotype and epigenotype induced by prenatal nutrition. J Nutr. (2009) 139:1054-60. doi: 10.3945/jn.109.1 04653

4. Gurven M, Walker R. Energetic demand of multiple dependents and the evolution of slow human growth. Proc Biol Sci. (2006) 273:835-41. doi: $10.1098 /$ rspb.2005.3380

5. Bock J. What makes a competent adult forager. In: Hewlett BS, Lamb ME, editors. Hunter-Gatherer Childhoods. Transaction Publishers, Rutgers University (2005). p. 109-28.

6. Arnett JJ. Emerging adulthood: a theory of development from the late teens through the twenties. Am Psychol. (2000) 55:469. doi: 10.1037/0003-066X.55.5.469
These realities highlight the adaptive advantages of a postadolescent or emerging adulthood phase of human maturation, which requires substantial brain maturation and learning.

Secular trends indicate that the duration of pre-adolescent growth and development has shortened over the past two centuries and a further decoupling between pubertal/hormonal maturation and brain maturation has occurred in adolescents in developed societies. The nutritional and social conditions which drive this trend have been previously discussed and reviewed (2). While the mental maturation of adolescents and emerging adults in developed societies is as slow or slower than that of those in predeveloped societies, the onset of puberty in the developed societies now occurs at a younger age than that in the predeveloped societies. Many people in advanced developed states have increasingly recognized the need for prolonged period of education and support beyond adolescence. Others in contrast, especially those in the developing world where traditional structural support systems have collapsed, are often not able to provide the experience of a protected emerging adulthood to their children, leading the United Nations to identify youth, defined as 15-24 years of age, as a demographic group at risk and a special target for intervention (11). The period of emerging adulthood has an evolutionary context and a prolonged maturational underpinning, and we present evidence that supports the idea that emerging adults require protection because they are still both learning and maturing. Yet, A literature review and hypotheses of that sort are based on associations. The prolonged dependency and frequent confusion of emerging adults in modern societies is not solely attributable to the complexity of our societies, but also to the fact that they are, intrinsically and physiologically, not yet adults.

\section{AUTHOR CONTRIBUTIONS}

$\mathrm{ZH}$ and $\mathrm{MK}$ jointly conceived the article, drafted the manuscript, read, and approved the final version.

7. Arnett JJ. Emerging adulthood (s). In: Jensen LA, editor. Bridging Cultural and Developmental Approaches to Psychology: New Syntheses in Theory, Research, and Policy. Oxford University Press (2010). p. 255-75.

8. Erikson EH. Identity: Youth and Crisis. New York, NY: Norton (1968).

9. Erikson EH. Childhood and Society. New York, NY: Norton (1950).

10. Hopwood CJ, Donnellan MB, Blonigen DM, Krueger RF, McGue M, Iacono WG, et al. Genetic and environmental influences on personality trait stability and growth during the transition to adulthood: a three-wave longitudinal study. J Personal Soc Psychol. (2011) 100:545. doi: 10.1037/a0022409

11. UNESCO. Youth Matters: Equipping Vulnerable Young People With Literacy and Life Skills. UNESCO Institute for Lifelong Learning Policy Brief 2. UNESCO Institute for Lifelong Learning/UIL Policy Briefs (2013). Available online at: http://unesdoc.unesco.org/images/0022/002230/223022e.pdf

12. Konner MJ. The Evolution of Childhood: Relationships, Emotion, Mind. Cambridge, MA: Harvard University Press (2010).

13. Hochberg Z. Evo-devo of child growth II: human life history and transition between its phases. Eur J Endocrinol. (2009) 160:135-41. doi: 10.1530/EJE-08-0445

14. Hochberg Z, Feil R, Constancia M, Fraga M, Junien C, Carel JC, et al. Child health, developmental plasticity, and epigenetic programming. Endocr Rev. (2011) 32:159-224. doi: 10.1210/er.2009-0039 
15. Cowan G, Pines D, Meitzer DE. Complexity: Metaphors, Models, and Reality. Boulder, CO: Westview Press (1994).

16. Lampl M. Human growth from the cell to the organism: saltations and integrative physiology. Ann Hum Biol. (2009) 36:478-95. doi: 10.1080/03014460902911670

17. Marshall WA, Tanner JM. Variations in the pattern of pubertal changes in boys. Arch Dis Childhood. (1970) 45:13-23. doi: 10.1136/adc.45.239.13

18. Marshall WA, Tanner JM. Variations in pattern of pubertal changes in girls. Arch Dis Childhood. (1969) 44:291. doi: 10.1136/adc.44.235.291

19. Shalet S. Stepping into adulthood: the transition period. Hormone Res Paediatr. (2004) 62:15-22. doi: 10.1159/000080904

20. Lantz H, Bratteby LE, Fors H, Sandhagen B, Sjostrom L, Samuelson G. Body composition in a cohort of Swedish adolescents aged 15, 17 and 20.5 years. Acta Paediatr. (2008) 97:1691-7. doi: 10.1111/j.1651-2227.2008.01035.x

21. Parker ST. Homo erectus infancy and childhood. In: Parker ST, McKinney ML, Langer J, editors. Biology, Brains, and Behavior: The Evolution of Human Development. The School of American Research Press (2000). p. 279-318.

22. Blakemore SJ, Choudhury S. Development of the adolescent brain: implications for executive function and social cognition. J Child Psychol Psychiatry. (2006) 47:296-312. doi: 10.1111/j.1469-7610.2006.01611.x

23. Petanjek Z, Judas M, Simic G, Rasin MR, Uylings HB, Rakic P, et al. Extraordinary neoteny of synaptic spines in the human prefrontal cortex. Proc Natl Acad Sci USA. (2011) 108:13281-6. doi: 10.1073/pnas.1105108108

24. Teffer K, Buxhoeveden DP, Stimpson CD, Fobbs AJ, Schapiro SJ, Baze WB, et al. Developmental changes in the spatial organization of neurons in the neocortex of humans and common chimpanzees. J Comp Neurol. (2013) 521:4249-59. doi: 10.1002/cne.23412

25. Miller DJ, Duka T, Stimpson CD, Schapiro SJ, Baze WB, McArthur MJ, et al. Prolonged myelination in human neocortical evolution. Proc Natl Acad Sci USA. (2012) 109:16480-5. doi: 10.1073/pnas.1117943109

26. Hill J, Inder T, Neil J, Dierker D, Harwell J, Van Essen D. Similar patterns of cortical expansion during human development and evolution. Proc Natl Acad Sci USA. (2010) 107:13135-40. doi: 10.1073/pnas.1001229107

27. Giedd JN, Blumenthal J, Jeffries NO, Castellanos FX, Liu H, Zijdenbos A, et al. Brain development during childhood and adolescence: a longitudinal MRI study. Nat Neurosci. (1999) 2:861-3. doi: 10.1038/13158

28. Giedd JN, Raznahan A, Alexander-Bloch A, Schmitt E, Gogtay N, Rapoport JL. Child psychiatry branch of the national institute of mental health longitudinal structural magnetic resonance imaging study of human brain development. Neuropsychopharmacology. (2015) 40:43-9. doi: $10.1038 / \mathrm{npp} .2014 .236$

29. Sowell ER, Thompson PM, Holmes CJ, Jernigan TL, Toga AW. In vivo evidence for post-adolescent brain maturation in frontal and striatal regions. Nat Neurosci. (1999) 2:859-61. doi: 10.1038/13154

30. Gur RC. Brain maturation and its relevance to understanding criminal culpability of juveniles. Curr Psychiatry Rep. (2005) 7:292-6. doi: 10.1007/s11920-005-0083-7

31. Scott ES, Steinberg L. Rethinking Juvenile Justice. Cambridge, MA: Harvard University Press (2008).

32. Steinberg L, Scott ES. Less guilty by reason of adolescence: developmental immaturity, diminished responsibility, and the juvenile death penalty. Am Psychol. (2003) 58:1009. doi: 10.1037/0003-066X.58.1 2.1009

33. Asato M, Terwilliger R, Woo J, Luna B. White matter development in adolescence: a DTI study. Cerebral Cortex. (2010) 20:2122-31. doi: $10.1093 /$ cercor/bhp282

34. Jolles DD, van Buchem MA, Crone EA, Rombouts SA. A comprehensive study of whole-brain functional connectivity in children and young adults. Cerebral Cortex. (2011) 21:385-91. doi: 10.1093/cercor/bhq104

35. Kelly AC, Di Martino A, Uddin LQ, Shehzad Z, Gee DG, Reiss PT, et al. Development of anterior cingulate functional connectivity from late childhood to early adulthood. Cerebral Cortex. (2009) 19:640-57. doi: 10.1093/cercor/bhn117

36. Lebel C, Beaulieu C. Longitudinal development of human brain wiring continues from childhood into adulthood. J Neurosci. (2011) 31:10937-47. doi: 10.1523/JNEUROSCI.5302-10.2011
37. Schaie KW, Willis SL, Caskie GI. The Seattle longitudinal study: relationship between personality and cognition. Neuropsychol Dev Cogn B Aging Neuropsychol Cogn. (2004) 11:304-24. doi: 10.1080/13825580490511134

38. Kail R, Salthouse TA. Processing speed as a mental capacity. Acta Psychol. (1994) 86:199-225. doi: 10.1016/0001-6918(94)90003-5

39. Haan N, Smith MB, Block J. Moral reasoning of young adults: politicalsocial behavior, family background, and personality correlates. J Personal Soc Psychol. (1968) 10:183. doi: 10.1037/h0026566

40. Steinberg L. Commentary: a behavioral scientist looks at the science of adolescent brain development. Brain Cogn. (2010) 72:160. doi: 10.1016/j.bandc.2009.11.003

41. Steinberg L, Morris AS. Adolescent development. J Cogn Educ Psychol. (2001) 2:55-87. doi: 10.1891/1945-8959.2.1.55

42. Leigh SR, Park PB. Evolution of human growth prolongation. Am J Phys Anthropol. (1998) 107:331-50. doi: 10.1002/(SICI)10968644(199811)107:3<331::AID-AJPA9>3.0.CO;2-\#

43. Bourguignon JP. Linear growth as a function of age at onset of puberty and sex steroid dosage: therapeutic implications. Endocr Rev. (1988) 9:467-88. doi: $10.1210 /$ edrv-9-4-467

44. Shea BT. The ontogeny of sexual dimorphism in the African apes. Am J Primatol. (1985) 8:183-8. doi: 10.1002/ajp.1350080208

45. Smith B, Tompkins RL. Toward a life history of the hominidae. Annu Rev Anthropol. (1995) 24:257-79. doi: 10.1146/annurev.an.24.100195.001353

46. Bonner J. Size and Cycle. Princeton, NJ: Princeton University Press (1965).

47. Bonner JT. Life Cycles: Reflections of an Evolutionary Biologist. Princeton, NJ: Princeton University Press (1993).

48. Hochberg Z. Developmental plasticity in child growth and maturation. Front Pediatr Endocrinol. (2011) 2:41. doi: 10.3389/fendo.2011.00041

49. West-Eberhard MJ. Phenotypic accommodation: adaptive innovation due to developmental plasticity. J Exp Zoolog B Mol Dev Evol. (2005) 304:610-8. doi: $10.1002 /$ jez.b.21071

50. Wrangham RW. The evolution of sexuality in chimpanzees and bonobos. Hum Nat. (1993) 4:47-79. doi: 10.1007/BF02734089

51. Bogin B, Smith BH. Evolution of the human life cycle. Am J Hum Biol. (1996) 8:703-16. doi: 10.4324/9780203789445-8

52. Anderson CM. Female age: male preference and reproductive success in primates. Int J Primatol. (1986) 7:305-26. doi: 10.1007/BF02736394

53. Goodall J. Through a Window: My Thirty Years With the Chimpanzees of Gombe. Houghton Mifflin Harcourt (2010).

54. Lancaster JB. Play-mothering: the relations between juvenile females and young infants among free-ranging vervet monkeys (Cevcopithecus aethiops). Folia Primatol. (1971) 15:161-82. doi: 10.1159/000155377

55. Kaplan H, Hill K. Hunting ability and reproductive success among male Ache foragers: preliminary results. Curr Anthropol. (1985) 26:131-3. doi: $10.1086 / 203235$

56. Kuester J, Paul A, Arnemann J. Age-related and individual differences of reproductive success in male and female Barbary macaques (Macaca sylvanus). Primates. (1995) 36:461-76. doi: 10.1007/BF02382869

57. Schwartz GT. Growth, development, and life history throughout the evolution of Homo. Curr Anthropol. (2012) 53:S395-S408. doi: $10.1086 / 667591$

58. Stearns SC. Trade-offs in life-history evolution. Funct Ecol. (1989) 3:259-68. doi: $10.2307 / 2389364$

59. Charnov E. Life History Invariants: Some Explorations of Symmetry in Evolutionary Ecology. (1993). Oxford: Oxford University Press.

60. Blurton Jones N, Hawkes K, O'Connell JF. Some current ideas about the evolution of the human life history. Compar Primate Socioecol. (2001) 22:140.

61. Pontzer H, Raichlen DA, Gordon AD, Schroepfer-Walker KK, Hare B, O'Neill MC, et al. Primate energy expenditure and life history. Proc Natl Acad Sci USA. (2014) 111:1433-7. doi: 10.1073/pnas.13169 40111

62. Eaton SB, Pike MC, Short RV, Lee NC, Trussell J, Hatcher RA, et al. Women's reproductive cancers in evolutionary context. Q Rev Biol. (1994) 69:353-67. doi: $10.1159 / 000084082$

63. Worthman CM. Evolutionary perspectives on the onset of puberty. Evol Med. (1999) 135-63. 
64. Herczeg G, Valimaki K, Gonda A, Merila J. Evidence for sex-specific selection in brain: a case study of the nine-spined stickleback. J Evol Biol. (2014) 27:1604-12. doi: 10.1111/jeb.12409

65. Allman J, McLaughlin T, Hakeem A. Brain weight and life-span in primate species. Proc Natl Acad Sci USA. (1993) 90:118-22. doi: $10.1073 /$ pnas.90.1.118

66. Wrangham RW. Catching Fire: How Cooking Made Us Human. New York, NY: Basic Books (2009).

67. Wrangham RW. Out of the pan, into the fire: how our ancestors' evolution dependend on what they ate. In: de Waal FBM, editor. Tree of Origin: What Primate Behavior Can Tell Us About Human Social Evolution. Cambridge, MA: Harvard University Press (2002). p. 119-43.

68. Marean CW, Bar-Matthews M, Bernatchez J, Fisher E, Goldberg P, Herries AI, et al. Early human use of marine resources and pigment in South Africa during the Middle Pleistocene. Nature. (2007) 449:905-8. doi: 10.1038/nature06204

69. Campbell B. Adrenarche and the evolution of human life history. Am J Hum Biol. (2006) 18:569-89. doi: 10.1002/ajhb.20528

70. Ross C, MacLarnon A. The evolution of non-maternal care in anthropoid primates: a test of the hypotheses. Folia Primatol. (2000) 71:93-113. doi: $10.1159 / 000021733$

71. Hrdy SB. Mothers and Others: The Evolutionary Origins of Mutual Understanding. Cambridge, MA: Harvard University Press (2009).

72. Lancaster JB, Lancaster C. Parental investment: the hominid adaptation. In: Ortner DJ, editor. How Humans Adapt. Washington, DC: Smithsonian Institution Press (1983). p. 33-65.

73. Lancaster J, Lancaster CS. The watershed: change in parental-investment and family- formation strategies in the course of human evolution. In: Lancaster J, Altmann, J, Rossi, AS, Sherrod, LR, editors. Parenting Across the Life Span: Biosocial Dimensions. New York, NY: Aldine De Gruyter (1987). p. 187-205.

74. Kaplan HS, Robson AJ. The emergence of humans: the coevolution of intelligence and longevity with intergenerational transfers. Proc Natl Acad Sci USA. (2002) 99:10221-6. doi: 10.1073/pnas.152502899

75. Leigh SR, Shea BT. Ontogeny of body size variation in African apes. Am J Phys Anthropol. (1996) 99:43-65. doi: 10.1002/(SICI)10968644(199601)99:1<43::AID-AJPA3>3.0.CO;2-0

76. Hochberg Z, Gawlik A, Walker RS. Evolutionary fitness as a function of pubertal age in 22 subsistence-based traditional societies. Int J Pediatr Endocrinol. (2011) 2011:2. doi: 10.1186/1687-9856-2011-2

77. Hawkes K. Grandmothers and the evolution of human longevity. Am J Hum Biol. (2003) 15:380-400. doi: 10.1002/ajhb.10156

78. Hawkes K, O'Connell JF, Rogers L. The behavioral ecology of modern hunter-gatherers, and human evolution. Trends Ecol Evol. (1997) 12:29-32. doi: 10.1016/S0169-5347(96)10060-4

79. Marlowe FW. A critical period for provisioning by Hadza men: implications for pair bonding. Evol Hum Behav. (2003) 24:217-29. doi: 10.1016/S1090-5138(03)00014-X

80. Marlowe F. The Hadza: Hunter-Gatherers of Tanzania. Berkeley, CA: University of California Press (2010).

81. Howell N. Life Histories of the Dobe !Kung. Berkley, MI: University of California Press (2010).

82. Cauffman E, Steinberg L. (Im)maturity of judgment in adolescence: why adolescents may be less culpable than adults. Behav Sci Law. (2000) 18:74160. doi: $10.1002 /$ bsl.416

83. Lebel C, Walker L, Leemans A, Phillips L, Beaulieu C. Microstructural maturation of the human brain from childhood to adulthood. Neuroimage. (2008) 40:1044-55.

84. Maclean JC, Covington R, Sikora Kessler A. Labor market conditions at school-leaving: long-run effects on marriage and fertility. Contemp Econ Policy. (2016) 34:63-88.

85. Sibly RM, Brown JH. Effects of body size and lifestyle on evolution of mammal life histories. Proc Natl Acad Sci USA. (2007) 104:17707-12. doi: 10.1073/pnas.0707725104

86. Kaplan H, Hill K, Lancaster J, Hurtado AM. A theory of human life history evolution: diet, intelligence, and longevity. Evol Anthropol Issues News Rev. (2000) 9:156-85. doi: 10.1002/1520-6505(2000)9:4<156::AID-EVAN5>3.0. $\mathrm{CO} ; 2-7$
87. Sisk CL, Foster DL. The neural basis of puberty and adolescence. Nat Neurosci. (2004) 7:1040-7. doi: 10.1038/nn1326

88. Buss DM. Sexual strategies theory: historical origins and current status. J Sex Res. (1998) 35:19-31. doi: 10.1080/00224499809551914

89. Beer R, Wagner F, Grishkevich V, Peshkin L, Yanai I. Towards an unbiased evolutionary platform for unraveling Xenopus developmental gene networks. Genesis. (2011) 50:186-191. doi: 10.1002/dvg.20811

90. Archer J. Sex differences in aggression in real-world settings: a meta-analytic review. Rev General Psychol. (2004) 8:291-322. doi: 10.1037/1089-2680.8.4.291

91. Angold A, Worthman C. Puberty onset of gender differences in rates of depression: a developmental, epidemiologic and neuroendocrine perspective. J Affect Disord. (1993) 29:145-58. doi: 10.1016/0165-0327(93)90029-J

92. Buchanan CM, Eccles JS, Becker JB. Are adolescents the victims of raging hormones: evidence for activational effects of hormones on moods and behavior at adolescence. Psychol Bull. (1992) 111:62-107. doi: 10.1037/0033-2909.111.1.62

93. Rutter M. Changing patterns of psychiatric disorders during adolescence. In: Bancroft J, Reinisch JM, editors. Adolescence and Puberty. New York, NY/Oxford: Oxford University Press (1990). p. 124-45.

94. Sisk CL, Zehr JL. Pubertal hormones organize the adolescent brain and behavior. Front Neuroendocrinol. (2005) 26:163-74. doi: 10.1016/j.yfrne.2005.10.003

95. Richards M, Petersen AC. Biological theoretical models of adolescent development. In: Van Hasselt VB, Hersen M, editors. Handbook of Adolescent Psychology. New York, NY: Pergamon Press (1987). p. 34-52.

96. Belsky J, Steinberg L, Houts RM, Halpern-Felsher BL, NICHD Early Child Care Research Network. The development of reproductive strategy in females: early maternal harshness $->$ earlier menarche $->$ increased sexual risk taking. Dev Psychol. (2010) 46:120-8. doi: 10.1037/a0 015549

97. Uchida A, Bribiescas RG, Ellison PT, Kanamori M, Ando J, Hirose N, et al. Age related variation of salivary testosterone values in healthy Japanese males. Aging Male. (2006) 9:207-13. doi: 10.1080/13685530601 060461

98. Martin D, Swenson R, Collins D. Correlation of serum testosterone levels with age in male chimpanzees. Steroids. (1977) 29:471-81. doi: 10.1016/0039-128X(77)90067-8

99. Finch CE, Rose MR. Hormones and the physiological architecture of life history evolution. Q Rev Biol. (1995) 70:1-52. doi: 10.1086/418864

100. Lessells C. The evolution of life histories. In: Davies NB, Krebs JR, editors. Behavioral Ecology: An Evolutionary Approach. 3rd ed. Oxford: Blackwell (1991). p. 32-68.

101. Boyce WT, Ellis BJ. Biological sensitivity to context: I. An evolutionarydevelopmental theory of the origins and functions of stress reactivity. Dev Psychopathol. (2005) 17:271-301. doi: 10.1017/S0954579405 050145

102. Bellis MA, Downing J, Ashton JR. Adults at 12? Trends in puberty and their public health consequences. J Epidemiol Commun Health. (2006) 60:910-1. doi: $10.1136 /$ jech.2006.049379

103. Olweus D, Mattson A, Schalling D, Low H. Testosterone, aggression, physical, and personality dimensions in normal adolescent males. Psychosomatic Med. (1980) 42:253-69. doi: 10.1097/00006842-198003000-00003

104. Olweus D, Mattsson A, Schalling D, Low H. Circulating testosterone levels and aggression in adolescent males: a causal analysis. Psychosom Med. (1988) 50:261-72. doi: 10.1097/00006842-198805000-00004

105. Fenner JN. Cross-cultural estimation of the human generation interval for use in genetics- based population divergence studies. Am J Phys Anthropol. (2005) 128:415-23. doi: 10.1002/ajpa.20188

106. Howell N. Demography of the Dobe Area !Kung. New York, NY: Academic Press (1979).

107. Shostak M. Nisa: the Life and Words of a !Kung Woman. Cambridge, MA: Harvard University Press (1981).

108. Howell N. Demography of the Dobe !Kung. 2nd ed. New York, NY: Aldine deGruyter (2000). 
109. Hurtado AM, Hill K, Hurtado I, Kaplan H. Trade-offs between female food acquisition and child care among hiwi and ache foragers. Hum Nat. (1992) 3:185-216. doi: 10.1007/BF02692239

110. Hawkes K, O’Connell F, Jones NB. Hadza children's foraging: juvenile dependency, social arrangements, and mobility among hunter-gatherers. Curr Anthropol. (1995) 688-700. doi: 10.1086/204420

111. Blurton Jones N, Marlowe FW. Selection for delayed maturity. Hum Nat. (2002) 13:199-238. doi: 10.1007/s12110-002-1008-3

112. Bird RB, Bird DW. Constraints of knowing or constraints of growing? Hum Nat. (2002) 13:239-67. doi: 10.1007/s12110-002-1009-2

113. Delemarre-van de Waal HA. Secular trend of timing of puberty. Endocr Dev. (2005) 8:1-14.

114. Garn SM. The secular trend in size and maturational timing and its implications for nutritional assessment. J Nutr. (1987) 117:817-23. doi: $10.1093 /$ jn/117.5.817

115. Belsky J, Steinberg L, Draper P. Childhood experience, interpersonal development, and reproductive strategy: and evolutionary theory of socialization. Child Dev. (1991) 62:647-70. doi: 10.2307/11 31166

116. Gluckman PD, Hanson MA. Evolution, development and timing of puberty. Trends Endocrinol Metab. (2006) 17:7-12. doi: 10.1016/j.tem.2005.11.006

117. Hochberg Z, Belsky J. Evo-devo of human adolescence: beyond disease models of early puberty. BMC Med. (2013) 11:113. doi: 10.1186/1741-7015-11-113
118. Brune M, Hochberg Z. Secular trends in new childhood epidemics: insights from evolutionary medicine. BMC Med. (2013) 11:226. doi: 10.1186/1741-7015-11-226

119. Simondon KB, Simondon F. Mothers prolong breastfeeding of undernourished children in rural Senegal. Int J Epidemiol. (1998) 27:490-4. doi: 10.1093/ije/27.3.490

120. Montagu A. Anthropology and Human Nature. Boston, MA: Porter Sargent Pub (1957).

121. American Academy of Pediatrics Committee on Adolescence, American College of Obstetricians and Gynecologists Committee on Adolescent Health Care, Diaz A, Laufer MR, Breech LL. Menstruation in girls and adolescents: using the menstrual cycle as a vital sign. Pediatrics. (2006) 118:2245-50. doi: 10.1542/peds.2006-2481

Conflict of Interest: The authors declare that the research was conducted in the absence of any commercial or financial relationships that could be construed as a potential conflict of interest.

Copyright (C) 2020 Hochberg and Konner. This is an open-access article distributed under the terms of the Creative Commons Attribution License (CC BY). The use, distribution or reproduction in other forums is permitted, provided the original author(s) and the copyright owner(s) are credited and that the original publication in this journal is cited, in accordance with accepted academic practice. No use, distribution or reproduction is permitted which does not comply with these terms. 